\title{
Gift Young Engineers: An Extra-Curricular Initiative for Updating Computer and Electrical Engineering Courses
}

\author{
Vicente Ferreira de Lucena Junior, José Pinheiro de Queiroz Neto, João Edgar Chaves Filho, \\ Waldir Sabino da Silva Junior and Lucas Carvalho Cordeiro
}

\begin{abstract}
The curricula of engineering courses are well defined by the central government for all Brazilian universities. Indeed, there are some mandatory determinations that must be fulfilled prior to the accreditation of any engineering course in Brazil. Modifications must be submitted for evaluation beforehand, resulting in a process that sometimes takes years to be approved. That is a secure way to guarantee that the fundamentals of each engineering program will be part of the students' carrier all over the country, and at the same time a problem when you need to introduce new technological subjects. That poses a problem when you have new demands for technological curricular components that could express the actual state of the art of modern subjects. Trying to solve these issues some professors from the Federal University of Amazonas developed a flexible extra-curricular program for electrical and computer engineering courses, named Gift Young Engineers. This paper describes the philosophy of these extra-curricular programs. Some examples of successful particular partnerships are also discussed. Indeed the proposed training programs for Digital TV Systems (hardware and software) will be presented and analyzed in details. The obtained results will also be discussed in order to contribute to similar experiences worldwide.
\end{abstract}

Index Terms - Extra-Curricular Programs; University and Industry Collaboration; Educational Experience.

\section{INTRODUCTION}

The curricula of Electrical and Computer Engineering courses are well defined by the central government, called ministry of education, for all Brazilian universities. Indeed, there are some mandatory determinations that must be fulfilled prior to the accreditation of any engineering course in Brazil. Curricular modifications must be submitted for evaluation, resulting in a process that sometimes takes years to be approved. In one hand that is a secure way to guarantee that the fundamentals of each engineering program will be part of the students' carrier, on the other hand new technological subjects may take a long time until they become part of those courses.
Many modern industries are installed in Manaus, a freezone city located in the middle of the Brazilian's Amazon rainforest. The city was once the most important rubber production center worldwide. It went through a long period of decadence up to the 60's when it became the home of the largest global free trade zone for the production of electronics and the Brazilian main manufacturing production center of analog and digital television sets. These companies need to hire engineers with knowledge of new technological trends demanding the introduction of new curricular components in the existing engineering courses. Most of these curricular components could not be implemented or took so long time to become part of the engineer courses that discourage any possible cooperation between the local industry and the universities [1].

Because of its history and characteristics, Manaus has many contrasts being the host of the oldest Brazilian University (UFAM) [2] and, at the same time, facing big problems in keeping a good level of education. Nowadays in Manaus we can count on several universities, technical colleges and research institutes which are responsible for the professional formation and the technological development to support the companies hosted in the local industrial pole. In fact, one of the biggest problems in the industrial pole of Manaus is to find professionals who fulfill all the necessary requirements of the employers. The experience of bringing professionals from other Brazilian cities has shown inefficient and expensive. People who come from other cities do not adapt easily to Manaus mainly because of its weather and its distance from other poles. The city is located in the middle of the Amazon Rain Forest, about 600 miles away from the next important city and has an average temperature of 80 grades Fahrenheit and a humidity factor over $80 \%$.

Therefore, the academy has been facing many difficulties in following the fast technological changes, for example, to keep up-to-date in areas such as embedded systems, new software technologies and more recently, Digital TV and related subjects. The curricula and the contents of the actual engineering majors are not adjusted to attend the research institutes brought to Manaus in recent years, as well as the new demands of classical electronic industries. On their side, the research institutions and the electro-electronic companies neither dispose of time nor of budget to train the professionals they need [3, 4, 5, 6].

October 12 - 15, 2011, Rapid City, SD 
Trying to solve these problems, some professors from the Federal University of Amazonas developed a flexible extra-curricular program for electrical and computer engineering courses, named Gift Young Engineers, that overcame the problems described above. The subjects, amount of hours, and the contents of each particular program were discussed with industry partners in order to attend their actual needs. The programs are always composed of two parts: a theoretical one covering the most significant topics, and a practical part when the students are supposed to solve real industrial problems. Some domains already worked out were related to the telephony industry, software for mobile devices, hardware and software for embedded systems, and more recently the development of hardware and software for Digital TV. The programs successfully attended the industry expectations with no further modification on the official courses' curricula [7, 8].

This paper describes the philosophy of these extracurricular programs. Some examples of successful partnerships are also discussed. The proposed training programs for Digital TV Systems (hardware and software) will be presented and analyzed in details. The obtained results will also be discussed in order to contribute to similar experiences worldwide.

\section{Main Characteristics of the Program}

The idea of the Gift Young Engineers program is to bring to the academy new subjects and the practical learning atmosphere necessary for real companies. The program is divided in two main parts. A theoretical one where all participating students are supposed to receive the most significant contents of the technology under consideration and a practical one when they should prove that they are fit to handle with all new learned subjects. The two parts are detailed as follow:

1- Theoretical training of the students, about six months five days a week and four hours per day. Such a program takes more than 400 hours to conclude. Initially, 30 students are selected and enrolled in this program. They are trained in the chosen technologies by specialized professors from UFAM and IFAM, two of the most important universities of Manaus. During the training, the students must take part in tests in each new topic. The obtained results are used to determine the students who will be able to continue.

2- Implementation of real projects, another six months with a working journey of about 20 hours per week. The selected students are divided in working teams and receive a project proposal. They are supposed to develop their project under the supervision of one academic adviser. Whenever is possible, an experienced industrial engineer joins the group and helps the faculty to guide the students work. This brings the project closer to the real world.

The decision of the topics that will be covered is done by a working group composed of expert faculties from both institutions (UFAM and IFAM) and engineers who need students to hire for their companies. This program implemented many different projects right now and served global companies like Nokia and Phillips, as well as local ones like Trópico (telecommunication) or Genius (research institute).

In this paper, the most recent project developed by our team is going to be described in details. It deals with hardware and software development for Digital TV systems. That is a very hot theme at this moment in Brazil once we are just moving from analog systems and there is a lack of well versed professionals in these related topics. The project was asked by CT-PIM a local government agency responsible for developing strategies to keep the industries in Manaus globally competitive.

The program is open to any engineer student living in Manaus. This fact makes the selection process a hard task. Indeed as soon as we defined the topics that would be covered, we proceeded with the verification of the graduate courses that could contain students with the desired profile. In the metropolitan area there are three public universities with courses in majors including electrical engineering, computer engineering and computer science. These public schools are well known and have a very good reputation. Additionally there are another 12 other private colleges offering diverse courses on computer science and other Information Technology related majors. The problem faced was how to select good students from this diversity of background choices and how to avoid privileging one school against the others.

The solution adopted since the beginning of the Gift Young Engineers program was to fix common criteria that could be fair for each institution: The students should preferably have completed $70 \%$ of their graduate studies; They should not have more than 2 fails in their academic history; They should prove basic knowledge of the English language; They should also prove basic knowledge in one or more programming languages; and at last their participation in under-graduated scientific projects had to be proved.

The invitation to participate in such a project is always announced via local newspapers and directly in the schools. Since the first projects in this program the expectation to receive many candidates was always fulfilled. Indeed the final results have been much optimistic than one could realize at the very beginning of this experience.

None of the students are allowed to stop their normal studies to participate in the program. They are also made aware that an increase on their scholar records is expected by the coordinators. In some cases, depending mostly on their school's regulations, the obtained results may be used as optional credits and even as final work thesis.

Another important characteristic of this project is that no fees are supposed to be paid by the students. They attend to the classes in the evening, four hours a day and five days per week. This means that they need to have time to be involved in an intensive work for six months. In the second part of the project they may change the working period and adapt it to the free time of the working team. In any case they need to work 20 hour per week, in fact the practice showed that they spend more time than the contractual one.

\section{$41^{\text {st }}$ ASEE/IEEE Frontiers in Education Conference}

\section{T1A-2}


In order to make the whole program more attractive, the sponsor companies agreed to pay a scholarship for each student during the practical phase. It means 20 scholarships for six months. This works properly once the students know that only the best participants will be able to continue in the program and only these ones will receive the respective monthly payment.

The faculties and other instructors involved in the program get paid by other research foundations like $\mathrm{CNPq}$, one agency belonging to the Brazilian Ministry of Science and Technology, or directly by the company sponsoring the specific project. Moreover when the desired topic being developed is not current in the university, new facilities are supposed to be constructed and equipped.

In the following sessions, we will show more details about one specific project that was developed under the Gift Young Engineers program at UFAM. As said before, the most recent we worked out was about Digital TV Systems.

\section{BACKGROUNDS OF DIGITAL TV SYSTEMS}

In order to attend to the demands posed by the local industry we constructed a program to skill our students in the very particular aspects of software and hardware development for Digital TV. Indeed, the technology used to construct digital TV systems is already discussed in the electrical engineering and in the computer engineering curricula in any classical engineering program. The problem is that the related topics are distributed in many courses all over the 5 years program.

In fact, some topics related to software development are very particular to the Brazilian TV system. To implement software applications to the DTV system it is necessary to get to know the standards used in the region and how to use already existing components, to deal with execution problems and how to test the desired platform. In the next paragraphs we will relate some particularities of the Brazilian system that will help the understanding of the educational program.

\section{Some concepts about Digital TV Systems}

A conventional DTV system is composed by three layers. The first one is called application layer and it is where the applications are implemented such as movies, e-mail, ecommerce, interactive games and other applications.

The second layer is the telecommunication service layer and its function is to get the multimedia transmission and the picture format. The main formats are: LDTV (Low Definition Television), which has low definition pictures for television services on mobile devices; SDTV (Standard Digital Television), that may use one of several different formats taking the form of various aspect ratios, depending on the technology used by the broadcasters; EDTV (Extended Definition Digital Television), that has better picture and sound quality than SDTV, but it doesn't reach up to the HDTV standards; and HDTV (High Definition Digital Television), the best picture resolution, but the most resource consuming to be transmitted over the air [9].
At last, the third layer is the software platform and it refers to the standard DTV definition, which is the set of technical specifications needed to the DTV operation, used to the development of interactive applications.

The standard adopted by the Brazilian DTV System is based on the Japanese ISDB including some advances and it is called ISDTV - International System for Digital TV [10]. The ISDTV brings together the resources of mobility, portability, high definition, data transmission and segmentation, which are the channel subdivisions that allow simultaneous transmission of programs in the same transmission channel.

ISDTV is formed by a set of components related to the application, signal codification, multiplexing and transmission. The reception of data occurs in the application layer, like video, audio and new interactive services. In the signal codification level, the video and audio signals are compressed using the systems MPEG-4 and MPEG-4ACC, respectively.

The novelty of the Brazilian system is its interface that supports the creation of interactive services through a particular middleware, which was developed by two Brazilian universities, Universidade Federal da Paraíba (UFPB) and Pontífícia Universidade Católica do Rio de Janeiro (PUC-Rio). Created to be open source software, the Brazilian middleware is called GINGA.

\section{The GINGA Middleware}

More specifically, the middleware is an interface between the applications and the operational system. It is also known as API (Application Programming Interface) which is intended to provide a standard for applications with no differences on the operating system layer and independently from the hardware that supports the services of decoding, modulation and transport.

GINGA is divided in two platforms, the first one called GING-J is used to support procedural applications written in the Java language; the second one, called GINGA-NCL, is used to support a declarative language called NCL (Nested Context Language) based in hypertext documents.

\section{Digital TV Emulator}

The process of embedding the applications consists of transporting the developed software to a specific DTV or to a set-top-box hardware platform [11]. However, for implementation of the educational prototypes used in this work and its validation tests, the use of an emulator is enough as a first stage. The emulator is installed on a desktop computer, and in practice it is an interface to test interactive television applications on the $\mathrm{PC}$, providing a simulation of a DTV environment.

In fact, the use of these emulators is a trivial task, and requires only some familiarity with the Java language [12]. The main motivation to use emulators is the easiness of the implementation, compared to the embedded application, and the fast return of the tests and their results [13].

\section{8-1-61284-469-5/11/\$26.00 C2011 IEEE}

October 12 - 15, 2011, Rapid City, SD

\section{1 $^{\text {st }}$ ASEE/IEEE Frontiers in Education Conference}




\section{DESCRIPTION OF THE Digital TV PROGRAM}

We developed two distinct branches for Digital TV under the Gift Young Engineers Program. The first was devoted to the software aspect of this new technology and the second covered the hardware part.

As described above the courses were divided in two different phases: Phase 1 covered the theoretical aspects of software development and of hardware development for Digital TV and the Phase 2 comprised the construction of a real project. In the next paragraphs a detailed description of the activities developed in the mentioned phases is going to be presented.

Before that we would like to briefly describe the student's selection process. Both projects had more candidates than we expected, indeed there were only 20 places available and there were more than 90 candidates inscribed, it meant that there were over 3 candidates for each place. We decided to accept some extra candidates for the theoretical phase opening 30 places for each course.

During the selection process the professors from UFAM and IFAM and the researchers from CT-PIM worked together. Among the 30 selected students (for each course) there were 6 different majors and 8 different schools. Well known colleges obtained not more than 5 approved students; even UFAM and IFAM, the hosts of this project, obtained only places for 5 and 4 of their students respectively.

\section{Phase 1: Teaching the Background Technologies}

The first phase of the training program consisted of 15 theoretical modules totalizing 400 hours of intensive class work for the Software for Digital TV branch and 13 modules with a total of 430 hours for the Hardware part. Tables I and II show the module names and the corresponding duration of each of them.

Clearly there is a division on the modules where about $30 \%$ covered the fundamental aspects for the desired technology and worked as a kind of level adjusting bringing all students, from different schools, to a common level of understanding of these fundamentals. The rest of the program covered deeper aspects concerning the specific technology being taught.

The classes were taught in the evening and we established some rules for the students. None of them were allowed to reduce the amounts of credits being attended in their normal courses during the day. They should also maintain their average grade showing that the participation in this project brought no prejudice for their normal academic lives.

All modules were conducted in a very practical basis. Classes took place in laboratories where no more than two students shared a computer. There were also enough working places for the hardware classes. As the lecturer explained a subset of topics and their related examples, the students could immediately explore them deeply by solving the practical exercises. This approach meets the "Learning by Doing" pedagogical focus normally adopted by IFAM.
TABLE I

MODULES OF THE SOFTWARE FOR DIGITAL TV PROGRAM

\begin{tabular}{|c|c|}
\hline Module & Duration (h) \\
\hline $\begin{array}{ll}\text { 1- } & \text { Fundamentals of Object Oriented } \\
\text { Programming }\end{array}$ & 20 \\
\hline $\begin{array}{l}\text { 2- Fundamental of Java Programming } \\
\text { Language }\end{array}$ & 20 \\
\hline 3- Logic, Algorithms and Data Structure & 20 \\
\hline 4- C Programming Language & 20 \\
\hline 5- Advanced Techniques using Java & 30 \\
\hline 6- C ++ Programming Languages & 40 \\
\hline 7- Software Engineering & 30 \\
\hline $\begin{array}{l}\text { 8- Linux OS and Programming Device } \\
\text { Drivers }\end{array}$ & 30 \\
\hline $\begin{array}{ll}\text { 9- } & \text { Project and Development of Embedded } \\
& \text { Systems }\end{array}$ & 30 \\
\hline $\begin{array}{l}\text { 10- J2ME - Java to Micro Edition } \\
\text { Programming }\end{array}$ & 20 \\
\hline 11- Fundamental of Digital TV Systems & 30 \\
\hline $\begin{array}{l}\text { 12- Multiplexing Data, audio and Video in } \\
\text { Digital TV Systems }\end{array}$ & 30 \\
\hline 13- Applied XML - Examples of Usage & 20 \\
\hline $\begin{array}{l}\text { 14- Fundamental of the Ginga Digital TV } \\
\text { Middleware }\end{array}$ & 30 \\
\hline 15- Java TV Programming & 30 \\
\hline Total & 400 \\
\hline
\end{tabular}

TABLE II

MODULES OF THE HARDWARE FOR DIGITAL TV PROGRAM

\begin{tabular}{|c|c|}
\hline Module & Duration (h) \\
\hline 1- Fundamentals of Digital Systems & 40 \\
\hline 2- Programming Logic and Algorithms & 30 \\
\hline 3- $\mathrm{C}$ and $\mathrm{C}++$ Programming Languages & 40 \\
\hline $\begin{array}{ll}\text { 4- } & \text { Fundamental of Microprocessors e } \\
\text { Microcontrollers }\end{array}$ & 40 \\
\hline 5- Real-Time Programming Techniques & 30 \\
\hline $\begin{array}{ll}6- & \text { Project and Development of Embedded } \\
\text { Systems }\end{array}$ & 30 \\
\hline $\begin{array}{l}\text { 7- Workshop on Microprocessors and } \\
\text { Microcontrollers Programming }\end{array}$ & 40 \\
\hline 8- Fundamental of Digital TV Systems & 20 \\
\hline 9- Digital TV Architecture & 40 \\
\hline $\begin{array}{l}\text { 10- Audio and Video Patterns for Digital TV } \\
\text { Systems }\end{array}$ & 40 \\
\hline $\begin{array}{l}\text { 11- Linux OS and Programming Device } \\
\text { Drivers }\end{array}$ & 30 \\
\hline $\begin{array}{l}\text { 12- Fundamental of the Ginga Digital TV } \\
\text { Middleware }\end{array}$ & 30 \\
\hline 13- Construction of Circuits Workshop & 20 \\
\hline Total & 430 \\
\hline
\end{tabular}

Evaluating the students was a matter defined personally by each professor. Minimal grade required in each module was 7,0 (in a scale from 0,0 to 10,0 ). Students who failed in two or more modules were not allowed to proceed.

\section{$41^{\text {st }}$ ASEE/IEEE Frontiers in Education Conference}




\section{Phase 2: Development of Industrial Projects}

The second phase of the project was planned to put the students in contact with the industrial know-how. The goal was to follow a real industry development process, by accessing its documentation and following the same phases used by real projects.

In this phase only the 20 best students of each project were able to continue. They received scholarships to cover their expenses and some extra money to pay their transportation and meals. That is exactly what they would receive in the local industries in case they were hired to work with them.

The industry staff played the role of customers, demanding products, while the students and the professors played the role of the project development teams. The projects developed by the students followed the main phases of the conventional life cycle of a product: a)Requirement specification; b)Architectural design; c)Implementation; d)Tests; and e)Packing and delivering.

Students generated and delivered working artifacts during each one of these five phases as follows:

- Requirement specification: creation of the technical requirements specification document, starting from the customer's requirements;

- Architectural design: elaboration of the technical solution document for the development, taking into account the time, scope and available resources;

- Implementation: implementation of the technical requirements in a specific programming language or hardware artifact and according to the desired architecture;

- Tests: elaboration of the test plan, test cases, test execution and fixing of bugs;

- Packing and delivering: generation of the final product baseline and the product delivery report to the customer.

Like a real project, the students had to adopt the development process and the documentation templates used by real companies, in this case the one used was the model of CETELI/UFAM. The work of the students was evaluated considering not only the quality of the delivered documents but also the capability of being on schedule.

Before the beginning of the development activities, the CT-PIM representatives and the faculties presented the projects' scopes to the students. After this presentation, each student received a questionnaire, where it was requested that they put in a decreasing order of priority the proposal that each other would like to develop. They should also explain the reasons for their priority choices. These questionnaires, together with the student's grades in the theoretical modules were used for the team composition. Indeed, the following three criteria were adopted: a) amount of people necessary to develop each proposal; b) the students' skills and the technology involved in the component development; c) student accomplishment in the theoretical modules. This procedure tried to align the students' interests and skills with the technical demands of each proposal, contributing with students' motivation and accomplishment. At the end three working groups were formed for the software part of the project and four groups worked in the hardware part, each of them having 4 to 7 students. The number of group members varied in accordance with the level of difficulty of the assigned task. Table III contains the title of the projects.

TABLE III

\begin{tabular}{|c|c|}
\hline Practical Project & Members \\
\hline \multicolumn{2}{|l|}{ SOFTWARE DEVELOPMENT } \\
\hline $\begin{array}{l}\text { 1- Interactive Game for Digital TV aiming } \\
\text { the Learning Process of Small Children }\end{array}$ & 7 \\
\hline $\begin{array}{l}\text { 2- A Digital TV Scheduler to Present the } \\
\text { actual Show in Mobile Phones }\end{array}$ & 6 \\
\hline $\begin{array}{l}\text { 3- Development of a Quiz Show to Digital } \\
\text { TV System integrated with Web Servers } \\
\text { and Return Channel }\end{array}$ & 7 \\
\hline \multicolumn{2}{|l|}{ HARDWARE DEVELOPMENT } \\
\hline $\begin{array}{l}\text { 1- Integration of Conventional Medical } \\
\text { Devices to Digital TV Systems - } \\
\text { Oximeters and Manometers } \\
\end{array}$ & 7 \\
\hline $\begin{array}{l}\text { 2- Adaptation of LUDO a Local Game to the } \\
\text { New Digital TV System }\end{array}$ & 4 \\
\hline $\begin{array}{l}\text { 3- Development of a Communication } \\
\text { System - Home Network - for Digital TV }\end{array}$ & 5 \\
\hline $\begin{array}{l}\text { 4- } \begin{array}{l}\text { Construction of an EPG - Electronic } \\
\text { Programming Guide for Digital TV }\end{array} \\
\end{array}$ & 4 \\
\hline
\end{tabular}

\section{RESUlTS AND CONCLUSION}

At the end of the project the students presented their work in an open conference at UFAM in the CETELI's auditorium. The prototypes worked well and proved to be good experiments for demonstrating the importance of Digital TV technology and its corresponding applications.

The most important result is that the totality of the students was able to conclude the training successfully. The teaching model proved to be a good extra-curricular approach where the students could attend to a large amount of classes in subjects related to their major but not exactly the same subjects they were used to study. They needed to handle their own programs and additionally participate in their training.

Another interesting result was the possibility to develop hardware and software prototypes together with other students from different engineering schools; this diversity is somehow the same they will face later on their professional lives. The groups developed real good jobs and established relations among different groups that would never meet without this project.

In fact, the students learned a lot about technologies related to Digital TV and learned how to develop hardware and software in a real world approach.

From our side, the group of professors from UFAM and IFAM needed to deal with many new pedagogical situations. For instance, teaching at the evening is quite different from doing the same job during the daylight. We needed to meet the right pace in order to guarantee that the students learning

\section{$41^{\text {st }}$ ASEE/IEEE Frontiers in Education Conference}


process would be good enough. Another challenge was to work with students having quite different backgrounds. The academic people needed to develop actions to guarantee a leveling of all participants prior to the beginning of the classes but also during the theoretical modules, as some of the students were not able to follow the classes without extra help. The fact that all of them were able to accomplish the program is certainly a very positive point of the project.

Additionally we learned a lot by working closer to the industry. The practical aspects and the industrial way of doing could be taught to the students as we worked with some colleagues of the sponsor companies.

Teaching software and hardware engineering for Digital TV Systems is not an easy task. It may cover a set of technologies and knowledge that could not be covered by only a few subjects. Additionally, the novelty of the theme is sometimes a problem for the faculties, that's why we grant to the joint venture of technical colleges and local research institutes the success obtained in our experience in Manaus.

In fact, there is no big novelty on the program adopted in this project; the modules and the sequence of their presentation obey a classical approach. The originality of our experience laid on the fact that we could join together students from 8 different schools and quite different backgrounds and even so obtained positive learning results. The division in two phases, where the second one was totaly oriented to the development of a real product is also an innovative contribution of our work.

\section{AKNOWLEDGGMENT}

We would like to thank very much SUFRAMA and CT-PIM for the financial support of this project and the $\mathrm{CNPq}$ (Conselho Nacional de Desenvolvimento Científico e Tecnológico) for the support of the professors involved. These institutions belong to the Brazilian Government and have been giving substantial support to the Universities located in Manaus and to its industrial and research pole. We would like to congratulate the staff from CT-PIM for the productive and cooperative work and also to thank you the participating students for the effort and the lots of hours dedicated to these projects.

\section{REFERENCES}

[1] Rovere, R. L., "Computing in the Brazilian Amazon", Commuications of ACM, Vol 35, No4., 1993, pp 21-24.

[2] Guinness Book of Records, 2005.
[3] Nooshabadi, S.; Garside, J., " Teaching Embedded Systems Design An International Collaborative Project", Proceedings of the 35th ASEE/IEEE Frontiers in Education Conference., 2005, pp 25-30.

[4] Ellis, H.J.C., and Hislop, G.W. Techniques for Providing Software Engineering Education to Working Professional. Proceedings of the $34^{\text {th }}$ ASEE/IEEE Frontiers in Education Conf. , Boston, USA, 2004.

[5] Lucena Jr, V., Brito, A., Göhner, P. and Jazdi, N.: A Germany-Brazil Experience Report on Teaching Software Engineering for Electrical Engineering Undergraduate Students. Proc. of the Conf. on Software Engineering Education and Training 2006, Turtle Bay, Hawaii, 2006.

[6] Brito, C.R.; Ciampi, M.M. "Distance learning designing new relations in engineering education", Frontiers in Education, 2004. FIE 2004. 34th Volume, Issue, 20-23 Oct. 2004 Page(s): T2C - 3-16 Vol. 1.

[7] Santos, D. Trindade, Vale, D. Terêncio, Meloni, L. G. Pedroso, "Digital TV and Distance Learning: Potentials and Limitations", Proceedings of the 36th ASEE/IEEE Frontiers in Education Conference, October 28 - 31, 2006, San Diego, CA.

[8] Lucena, F.V., Queiroz-Neto, J.P., Benchimol, I.B., Mendonça, A.P., Silva, V.R., Filho, M.F., "Teaching Software Engineering for Embedded Systems: an Experience Report from the Manaus Research and Development Pole". Proceedings of the $37^{\text {th }}$ ASEE/IEEE Frontiers in Education Conference, Milwaukee, USA, 2007.

[9] Morris and Smith-Chaigneau, "Interactive TV Standards - A Guide to MHP, OCAP and JavaTV”, Focal Press, Elsevier, 2005.

[10] Costa, J.R and Lucena Jr., V.F, "EMTV - A Component-Based DTV Middleware Extesnion for Educational Purpose", Lecture Notes in Computer Science, EuroITV 2008, Volume 5066, pp 219-228, 2008.

[11] Carvalho, C.B, Lucena Jr., V.F, Sabino, W.S. and dos Santos Jr., A.F. "Towards the Generation, Analyze and Validation of MPEG-2 Transport Stream Based on Free-Software Tools for the Brazilian Digital TV System", Jornadas de Sistemas de Telecomunicaciones, JST 2008, Quito - Equator, May 2008.

[12] Morris and Smith-Chaigneau, "Interactive TV Standards - A Guide to MHP, OCAP and JavaTV”, Focal Press, Elsevier, 2005.

[13] Costa, J.R and Lucena Jr., V.F, "An Educational Component-Based Digital TV Middleware for the Brazilian's System", Lecture Notes in Computer Science, Edutainment 2008, Volume 5093, pp 41-51, 2008.

\section{AUTHOR INFORMATION}

Vicente Ferreira de Lucena Junior, Professor at the University of Amazonas (UFAM) and at the Federal Institute of Amazonas (IFAM), both in Manaus. He has been developing research activities at CETELI - UFAM vicente@ufam.edu.br or lucena@ifam.edu.br

José Pinheiro de Queiroz Neto, Professor at the Federal Institute of Amazonas (IFAM), pinheiro@ifam.edu.br

João Edgar Chaves Filho, Professor at the University of Amazonas (UFAM), jo_edgar@ufam.edu.br

Waldir Sabino da Silva Junior, Professor at the University of Amazonas (UFAM), waldirjr@ufam.edu.br

Lucas Carvalho Cordeiro, Professor at the University of Amazonas (UFAM), lucascordeiro@ufam.edu.br 